\title{
TAKE ME BACK TO MOVE ME FORWARD: RE-ENACTMENT OF THE FAMILY SYSTEM AS A PATHWAY TO BETTER QUALITY OF LIFE FOR ALEXITHYMIC PATIENTS IN GROUP THERAPY
}

\author{
John S. Ogrodniczuk ${ }^{1}$, Joanna Cheek ${ }^{1}$, David Kealy ${ }^{1}$ \& Ingrid Söchting ${ }^{1,2}$ \\ ${ }^{I}$ Department of Psychiatry, University of British Columbia, Vancouver, Canada \\ ${ }^{2}$ Department of Psychology, University of British Columbia, Vancouver, Canada
}

received: 15.11.2018;

revised: 12.3.2019;

accepted: 24.4 .2019

\section{SUMMARY}

Background: Despite much attention in the clinical literature, research on alexithymia in the treatment setting has only recently gained traction. While several reports indicate limited benefit from therapy amongst patients with high alexithymia, this seems to be less so in the context of group therapy. This study considers a specific aspect of the group therapy process - family re-enactment - in facilitating improvement in overall quality of life for patients with high levels of alexithymia.

Subjects and methods: Family re-enactment was examined as a potential mediator of the relationship between alexithymia and change in quality of life among 50 patients who completed treatment in an intensive, integrative group therapy programme. Patients completed three self-report measures: Toronto Alexithymia Scale-20 (baseline), Quality of Life Inventory (baseline, post-therapy), and Therapeutic Factors Inventory-Short Form (week 8). Regression with mediation analysis was employed using the change score for the QOLI as the dependent variable, alexithymia scores as the independent variable, and the family re-enactment score as the mediator; baseline quality of life was included in the model as a control variable.

Results: Family re-enactment emerged as a significant mediator of the relationship between alexithymia and treatment outcome, implicating it as a contributing mechanism of change for alexithymic patients who participate in group therapy.

Conclusion: Patients with higher levels of alexithymia (in particular, difficulty identifying and describing feelings) were more likely to positively endorse aspects of family re-enactment during group therapy, which in turn were significantly associated with greater improvement in patients' overall quality of life.

Key words: alexithymia - group therapy - family re-enactment - mediation

$$
* * * * *
$$

\section{INTRODUCTION}

All psychotherapies, in one way or another, require patients to differentiate, verbalise, and discuss subjecttive experiences and feelings. However, some patients have great difficulty identifying and expressing feelings or emotional aspects of their life experiences. Such patients may suffer from alexithymia, a trait deficit in the cognitive processing of emotional experience, such that individuals have a limited capacity to symbolise emotions and elaborate upon emotional experience (Taylor et al. 2016). Indeed, authors have considered the difficulties in treating alexithymic patients since the earliest conceptualizations of the construct (Nemiah \& Sifneos 1970, Sifneos 1973). Individuals with alexithymia have difficulty presenting material spontaneously, tend to use vocabulary of limited complexity, and their emotional discourse lacks vivid descriptions (Meganck et al. 2009). Their thinking tends to be concrete and focused on external events, with limited capacity for abstraction, metaphorical thinking, and fantasy (Kreitler 2002). Individuals with high levels of alexithymia also struggle with connecting physical arousal or somatic symptoms with psychic distress (Taylor 2010), and are less likely to perceive themselves as active agents in control over their own health (Hungr et al. 2016). Patients with high levels of alexithymia often know that they don't feel good, but don't know how to say or describe what they're feeling.
Several theorists have speculated that the deficits associated with alexithymia stem from maladaptive early life experiences, often associated with dysfunctional parenting. Maltreatment, excessive caretaker attention to a child's bodily rather than emotional needs, and caretaker emotional unavailability or inconsistency have been posited as contributing to the disturbed affect representation and self-regulation of alexithymia (Lumley et al. 1996). A growing body of evidence supports such conjectures (Karukivi \& Saarijärvi 2014). For example, Berenbaum and James (1994) found that young adults' reports of diminished family expressiveness (specifically, limited positive communication) were related to their own affective identification and communication deficits. A seminal study by Lumley and colleagues (1996) found that difficulty identifying feelings was related to dysfunctional family affective involvement, externally oriented thinking was related to deficient family behaviour control, and impaired imagination was related to inadequate family problem solving. A study by King and Mallinckrodt (2000) demonstrated not only that family dysfunction (parent-child role reversal, fear of separation, parental enmeshment) was associated with higher levels of alexithymia, but also that healthy family environments (cohesiveness, emotionally expressive, encouraging of independence) were related to lower levels of alexithymia. More recently, Gatta and colleagues (2017) reported that parents' alexithymic 
traits, combined with children's perception of a neglectful parenting style, were linked with emotional difficulties associated with alexithymia in offspring. Their findings suggest that parents' difficulties in describing their own emotions can limit their children's capacity to develop their own emotional and imaginative life that need to be supported by a close sharing of their feelings with their parents (Taylor et al. 1997).

Considering the importance of working with emotional experiences in psychotherapy and the challenges that alexithymic patients have in processing emotional information, treatment may only be partially successful. The difficulties underlying the patient's presenting problems may not be adequately disclosed or examined, let alone addressed and resolved, and might continue to burden the patient long after treatment has ended (Ogrodniczuk et al. 2004). A recent review of the literature exploring the influence of alexithymia on treatment outcomes (Ogrodniczuk et al. 2018) found mixed results. A handful of studies reported no effect of alexithymia on the outcome of therapy, but twice as many studies reported a negative effect. Though not a uniform phenomenon, the findings suggest that clinicians can reasonably presume that highly alexithymic patients might struggle to derive full benefit from treatment. It is important to note that the studies that found alexithymia to have a negative influence on therapeutic outcomes indicated that higher alexithymia scores correlated with lower outcome scores or that alexithymic patients derived less improvement in outcomes compared to non-alexithymic patients, not that patients with higher alexithymia scores made no therapeutic gains or got worse after treatment. The review also found that no psychotherapy treatment could be identified as being superior for alexithymic patients; however, the majority of studies demonstrating significant benefit for such patients included a group therapy component.

Considering the research evidence that points to a connection between dysfunctional family experiences and alexithymia, one therapeutic element of group therapy stands out as a possible reason for why group therapy may be an especially useful form of treatment for alexithymic patients: the corrective recapitulation of the primary family group, also known more simply as family re-enactment. Considered a core therapeutic factor of group therapy (Yalom \& Leszcz 2005), family re-enactment refers to the process whereby patients explore childhood experiences, roles, behaviours, and feelings within the social microcosm of the group. Using the dynamics of the group, patients can investigate old dysfunctional patterns of their family of origin, receive validation and empathy, and learn new behaviours and ways of relating. For alexithymic patients, this process may allow them to understand how their early family life experiences may have limited their capacity to share, understand and regulate their emotions, observe and model other group members who are able to talk about their emotions more effectively, and improve their ability to communicate their emotional experiences in a way that enhances life functioning.

To our knowledge, no previous study has examined the potentially facilitative function of family reenactment for patients with high levels of alexithymia who undertake group therapy. Thus, the purpose of the present study was to investigate whether patients' perceptions of family re-enactment experiences in group therapy mediated the relationship between alexithymia and treatment outcome.

\section{SUBJECTS AND METHODS}

\section{Participants}

Participants $(\mathrm{N}=50)$ were consecutively admitted patients to an integrative group therapy program located at Richmond Hospital in Richmond, British Columbia, Canada. Family doctors and psychiatrists refer patients with primarily mood, anxiety, and personality difficulties, who are capable of independent functioning but have difficulties meeting expectations and demands at work and at home. Many are on stress or disability leave as they seek help to return to their previous level of functioning. Criteria for inclusion in the program were 18 years of age or older, ability to set goals for treatment, and to commit to regular and punctual attendance. Patients were excluded from the program if they were acutely suicidal or homicidal, displayed antisocial behaviours, or presented with psychotic disorders or substance use disorders. Because the program was designed to serve a heterogeneous outpatient population, diagnostic assessments are not performed. Comprehensive case formulations, rather than diagnoses, are used to guide patients' treatment in the program. The study was approved by two local health research ethics review committees and subjects participated with informed, voluntary written consent. Because the program is located with an academic research and training centre, research is a typical part of the program activities, and patients are typically enthusiastic about participating in research. Because assessment of alexithymia occurred following written consent, we cannot ascertain whether there was a difference in alexithymia between those who did and did not agree to participate. However, very few patients declined to participate, thus we have no reason to suspect a selection bias related to research participation.

The average age of the patients was 43.0 years $(\mathrm{SD}=11.24$, range=19-61). Seventy-six percent were women. With regard to marital status, $50 \%$ were married or living with a partner, $16 \%$ were separated or divorced, $2 \%$ were widowed, and $32 \%$ were single. Seventy-two percent were educated beyond high school, and $54 \%$ were employed. Many patients (92\%) reported receiving previous psychiatric treatment; but only a small proportion of patients (14\%) had a history of psychiatric hospitalization. 


\section{Treatment}

Treatment consisted of an intensive outpatient, integrated group therapy program that serves patients with a variety of problems. The program is time-limited with 17 patients attending for three hours per day, five days a week, for 12 weeks. The program uses rolling admissions, and each week one or two new patients enter as others are discharged, with the overall number staying constant at 17. There is a long wait list for this intensive group program, ensuring that any drop-outs are replaced within a week. All patients get the same amount of therapy for 12 weeks with no individually-tailored subtreatment programs. Although predominantly guided by cognitive-behaviour theory, the program includes groups from other orientations such as psychodynamic and interpersonal therapy (see Table 1). Each specific group is held at the same weekly time(s) and conducted by the same facilitator(s) with specialized training and competence in their particular group. This allows for the group facilitator(s) to take ownership of their particular groups and challenge themselves to practice within their scope and specialized training. For example, twice a week (Tuesday and Thursday) a psychiatrist leads the Psychodynamic Group along with a psychiatric nurse as co-facilitator, and an occupational therapist leads the Goal Setting group every Monday morning. This ensures a great deal of constancy and predictability for the patients. The groups have different therapeutic tasks and focus on topics such as goal setting, problem solving, assertiveness and anger management, intimacy and relationships, and impact of family of origin dynamics. Each component of the program is manualised, with varying degrees of structure defined by the various manuals. For example, the Anger Management Group follows a highly specific session-by-session protocol, whereas the Psychodynamic Group, by definition, is unstructured in terms of weekly topics. The various groups (a total of ten per week) run sequentially, with two groups per day following a set weekly schedule. For example, Monday's schedule consists of the Weekend Review Group and the Goal Setting Group, whereas Tuesday's schedule consists of the Leisure Education \& Social Interaction Group and Psychodynamic Group. The program staff $(\mathrm{N}=7$, totaling 2.0 full-time positions) consists of clinicians from the disciplines of psychology, psychiatry, social work, nursing, occupational and recreational therapy. A psychiatrist is available for medication management, as most patients are on a stable dose of medication (typically an antidepressant) upon entry into the program. All patients participate in all modules together and receive an identical amount and content of therapy. No individual therapy is offered as part of the program. All patients are reviewed in weekly case conferences with all group therapists attending. This allows all therapists to express their views and reflections on each patient, the group composition, and the overall group climate. It also ensures patients are using the various group treatment components optimally. For example, a patient may address psychological barriers to following through with their goal of walking daily in the psychodynamic group. In addition, individual patient progress is reviewed on an ongoing basis on a secure electronic charting server where all therapists involved with the patient can offer their comments and observations, which are shared with the rest of the team.

Table 1. Overview of program

\begin{tabular}{|c|c|c|c|c|c|c|}
\hline & & Monday & Tuesday & Wednesday & Thursday & Friday \\
\hline $\begin{array}{l}\text { Group } 1 \\
\text { (10:00am } \\
11: 30 \mathrm{am})\end{array}$ & - & $\begin{array}{l}\text { Weekend Review } \\
\text { - reflection on } \\
\text { activities from } \\
\text { the weekend and } \\
\text { degree to which } \\
\text { goals were met. }\end{array}$ & $\begin{array}{l}\text { Leisure Education } \\
\& \text { Social } \\
\text { Interaction } \\
\text { - psychoeducation } \\
\text { centred around } \\
\text { recreation and } \\
\text { social engage- } \\
\text { ment. }\end{array}$ & $\begin{array}{l}\text { Understanding and } \\
\text { Coping with } \\
\text { Depression } \\
\text { - cognitive-beha- } \\
\text { vioural approach to } \\
\text { identifying and } \\
\text { modifying mal- } \\
\text { adaptive thoughts } \\
\text { and behaviours }\end{array}$ & $\begin{array}{l}\text { Problem Solving } \\
\text { - psychoeducation } \\
\text { approach to deve- } \\
\text { loping helpful } \\
\text { problem solving } \\
\text { skills, and practi- } \\
\text { cing such skills } \\
\text { on discrete pro- } \\
\text { blems with the } \\
\text { group's help. }\end{array}$ & $\begin{array}{l}\text { Intimacy and } \\
\text { Relationships } \\
\text { - focus on present } \\
\text { relationships, } \\
\text { with a more } \\
\text { behaviourally } \\
\text { oriented approach } \\
\text { to developing } \\
\text { intimacy within } \\
\text { relationships. }\end{array}$ \\
\hline $\begin{array}{l}\text { Group } 2 \\
\text { (12:30pm } \\
2: 00 \mathrm{pm})\end{array}$ & & $\begin{array}{l}\text { Goal Setting } \\
\text { - setting new } \\
\text { goals for the } \\
\text { week. }\end{array}$ & $\begin{array}{l}\text { Psychodynamic } \\
\text { - interpretive exa- } \\
\text { mination of rela- } \\
\text { tionship patterns } \\
\text { and associated } \\
\text { wishes, anxieties, } \\
\text { and defenses. } \\
\text { Exploring impact } \\
\text { of family of } \\
\text { origin dynamics. }\end{array}$ & $\begin{array}{l}\text { Assertiveness and } \\
\text { Anger Management } \\
\text { - behaviourally } \\
\text { oriented approach } \\
\text { to being appropria- } \\
\text { tely assertive in } \\
\text { interpersonal set- } \\
\text { tings and also } \\
\text { appropriately } \\
\text { managing one's } \\
\text { anger. }\end{array}$ & $\begin{array}{l}\text { Psychodynamic } \\
\text { - interpretive } \\
\text { examination of } \\
\text { relationship pat- } \\
\text { terns and associa- } \\
\text { ted wishes, anxie- } \\
\text { ties, and defenses. } \\
\text { Exploring impact } \\
\text { of family of } \\
\text { origin dynamics. }\end{array}$ & $\begin{array}{l}\text { Goal Setting } \\
\text { - setting new } \\
\text { goals for the } \\
\text { weekend - to be } \\
\text { reviewed on } \\
\text { Monday morning. }\end{array}$ \\
\hline
\end{tabular}


An integrated group program that offers patients a variety of intensive and coordinated group activities may be particularly useful for alexithymic patients. That is, different group interventions that employ diverse, but complementary, strategies for understanding emotional experiences can provide alexithymic patients with the behavioural, cognitive, and affective skills necessary to effectively perceive, reflect on, and communicate affectively laden mental states.

\section{Assessments and procedures}

Three self-report measures were used for the purpose of this study. These consisted of the Toronto Alexithymia Scale-20 (TAS-20; Bagby et al. 1994), the Quality of Life Inventory (QOLI; Frisch 1994), and the Therapeutic Factors Inventory-Short form (TFI-S; MacNair-Semands et al. 2010).

Alexithymia was assessed using the Toronto Alexithymia Scale-20 (TAS-20; Bagby et al. 1994). The 20 items of the TAS-20 are rated on a 5-point scale ranging from 1 (strongly disagree) to 5 (strongly agree). In addition to a total score, the TAS-20 yields scores for three dimensions of alexithymia: (1) difficulty identifying feelings; (2) difficulty communicating feelings; and (3) externally oriented thinking. Higher scores indicate higher levels of alexithymic traits. The factor structure, internal consistency, and validity of the TAS20 are well established (Quilty et al. 2017, Watters et al. 2019). Patients completed the TAS-20 at baseline.

Quality of life, representing treatment outcome in the present study, was assessed using the QOLI (Frisch 1994), which measures satisfaction in 16 life domains (e.g., health, work, friendships). Participants provide an importance rating $(0=$ not important, $1=$ important, $2=$ extremely important) and satisfaction rating $(-3=$ very dissatisfied to $3=$ very satisfied) for each domain. A total life satisfaction score is computed by averaging all the subscale scores for the domains that were rated as either important or extremely important. Higher scores reflect better quality of life. The QOLI has satisfactory and robust psychometric properties (Thomas et al. 2012). Patients completed the QOLI at baseline and at post-therapy.

Family re-enactment was assessed using the Therapeutic Factors Inventory-Short Form (TFI-S; MacNairSemands et al. 2010), a 44-item questionnaire that measures group members' perceptions of eleven group therapeutic factors, as described by Yalom and Leszcz's (2005). For the present study, the family re-enactment subscale was used (sample item: In group, I've started being able to break old patterns learned in my family). Group members rate the extent to which they agree with statements that are intended to reflect the presence or absence of the therapeutic factors. Items on the TFI-S are rated using a seven-point scale ranging from 1 ('strongly disagree') to 7 ('strongly agree'), with subscale total scores ranging from 4-28. Internal consistency for the family re-enactment subscale is acceptable (alpha $=0.79$ ). Patients completed the TFI-S at week 8 of treatment.

\section{Statistical analyses}

Analyses were performed using SPSS version 24, including the PROCESS macro (Hayes 2018). Zeroorder correlations were computed to examine simple relationships between all variables in the study, and a paired samples t-test was performed to evaluate overall change in QOLI scores over treatment. Regression with mediation analysis was employed using the change score (pre-post) for the QOLI as the dependent variable (Y), each of the alexithymia scores as the independent variable $(\mathrm{X})$, and the family re-enactment score from the TFI-S as the mediator (M); the baseline QOLI score was included in the model as a control variable. In keeping with contemporary understanding of mediation (Hayes \& Rockwood 2017), a significant direct effect between alexithymia and quality of life was not required in order to demonstrate the indirect effect of alexithymia through family re-enactment. Bootstrapped percentile 95\% confidence intervals (CI) were estimated, using 5,000 resamples. The statistical significance of an indirect effect of alexithymia - via family re-enactment - on quality of life would thus be indicated by the CI not including zero.

\section{RESULTS}

Table 2 shows the bivariate correlations between alexithymia, family re-enactment, and quality of life. On average, patients experienced significant improvement in their quality of life following participation in the group therapy program $(t=-6.89, d f=49, p<0.001)$.

Results of regression analyses involving the overall alexithymia score (Table 3), controlling for baseline quality of life, indicated that alexithymia had a significant association with family re-enactment. With all variables entered into the model, alexithymia was not significantly related to change in quality of life. However, a significant indirect effect (indicating a mediation effect) was observed for alexithymia on quality of life through family re-enactment. This finding suggests that greater awareness of how family of origin dynamics influence one's current functioning - which was more evident for those with higher levels for alexithymia - contributes to greater improvement in quality of life.

Further mediation analyses revealed similar findings for two of the alexithymia dimensions; difficulty identifying feelings and difficulty describing feelings (see Table 3). As with overall alexithymia, difficulty identifying feelings and difficulty describing feelings were each significantly associated with family re-enactment, but were not directly associated with change in quality of life with all other variables entered into the model. Yet, a significant indirect effect (indicating a mediation effect) was observed for each alexithymia dimension on quality of life through family re-enactment. 
Table 2. Descriptive statistics and zero-order correlations between alexithymia, family re-enactment, and quality of life

\begin{tabular}{lcccc}
\hline & $\mathrm{M}(\mathrm{SD})$ & 1 & 2 & 3 \\
\hline 1. Alexithymia total score & $60.97(10.74)$ & & & \\
2. Family re-enactment & $20.78(4.44)$ & $0.34^{*}$ & & \\
3. Quality of Life (baseline) & $-0.99(1.36)$ & -0.09 & -0.26 & \\
4. Quality of Life (post-therapy) & $0.76(1.71)$ & -0.02 & 0.18 & $0.33^{*}$ \\
\hline$* p<0.05$ & & &
\end{tabular}

Table 3. Results of regression analyses examining the indirect effect of alexithymia on quality of life, through family re-enactment as mediator

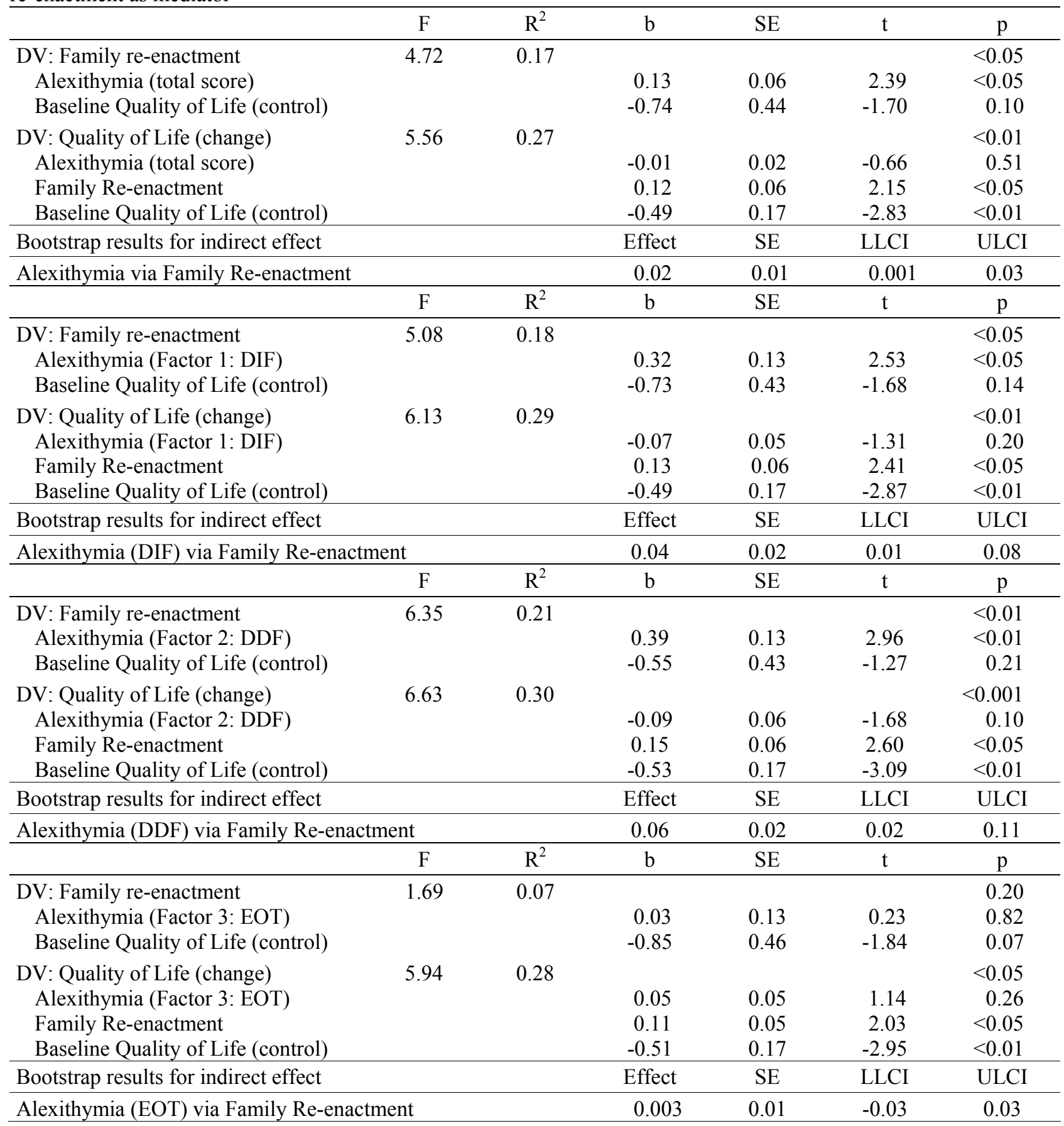

Note: number of bootstrap samples $=5,000 ; 95 \%$ bias corrected confidence intervals;

DIF: Difficulty Identifying Feelings; DDF: Difficult Describing Feelings; EOT: Externally Oriented Thinking 


\section{DISCUSSION}

It has often been reported that alexithymia has a negative impact on the outcome of psychotherapy; however, results from our study indicated that alexithymia had minimal direct effect on patients' response to an integrative group therapy program. Interestingly, a recent review (Ogrodniczuk et al. 2018) concluded that two-thirds of studies that have reported no negative impact of alexithymia on treatment outcome involved group-based treatments. Some authors have speculated that emotional arousal may be diluted by the presence of other group members, and may be less threatening and less likely to be expressed somatically by patients with high levels of alexithymia (Swiller 1988). Group therapy also provides an opportunity to observe and model other group members who are able to talk about their emotions more effectively (Cameron et al. 2014).

Findings from the present study suggest that yet another feature of group therapy may be at play in facilitating alexithymic patients' responses to group therapy. Family re-enactment emerged as a significant mediator of the relationship between alexithymia and treatment outcome, implicating it as a contributing mechanism of change for alexithymic patients who participate in group therapy. The findings revealed that patients with higher levels of alexithymia (in particular, difficulty identifying and describing feelings) were more likely to positively endorse aspects of family re-enactment during group therapy, which in turn were significantly associated with greater improvement in patients' overall quality of life.

The work of Harry Stack Sullivan (1953) considered the crucial roles that others play in not only contributing to illness formation, but also in facilitating healing; describing how it takes people to make people sick, and therefore it takes people to make people well again. If disruptions in early patterns of attachment and healthy modelling from caregivers are potential contributing factors for alexithymia, then constructively working within a group setting to remediate these factors could help ameliorate the deficits. Thus, exploring alexithymic individuals' family experiences (e.g. roles, behaviours, and feelings) as they come alive within the social microcosm of the group can help to identify old internalized dysfunctional family patterns that may have fuelled the patients' initial presentation of alexithymia, and practice healthier ways of relating to their own affective states and to others.

The group provides a rich opportunity for individuals to become immersed in a variety of transference reactions, including vertical - recapitulating parental figures, horizontal - recapitulating siblings or peers, and more complicated triangulations and other configurations of the family (Rutan et al. 2014). Then, as these internalized ways of reacting and relating to others impact the group, multiple sources - both from the leader(s) and peers - can repeatedly provide constructive interpersonal feedback and reinforce new learning from many interpersonal planes. For example, alexithymic individuals may learn how their alexithymia is negatively experienced by others in a variety of ways or how it obstructs their ability to get their needs met by the group. In this way, individuals can learn how certain ways of thinking and behaving (those related to alexithymic tendencies) may have been helpful adaptations to their family of origin in the past, but no longer serve them in the present. The group can provide validation and empathy for the adaptive role alexithymia may have played in the past, while teaching and demonstrating more helpful ways of identifying, modulating, and communicating their internal life.

This study examined a multifaceted group program that offered an integrated approach of complimentary group activities including psychodynamic, cognitive behavioural (CBT) and interpersonal therapy (IPT) components. Consequently, further studies could help delineate the specific components of the program that particularly enhance the family re-enactment dimension. For example, is the explicit focus on transference - including interpretively connecting it to the individual's family of origin - a necessary aspect of the psychodynamic component of such a program? Or do IPT interventions, with their present-oriented focus on current interpersonal situations outside of the group (without explicitly interpreting transference), suffice? Similarly, what role do CBT interventions play, such as the didactive review of the cognitive model of depression, in encouraging group members to further their reflection and emotional processing of developmental cognitive antecedents (e.g., messages from their caregivers during formative years)? It may be that these component-based interventions could work differently for different patients in helping to rework old family-based patterns, or that common mechanisms such as safety and trust in a group setting - are more responsible for activating such changes. Further research is needed regarding specific techniques (for example, the presence or quantity of explicit interventions addressing family re-enactment) and common factors to shed light on this issue. Furthermore, to what extent can family re-enactment improve outcome in individual therapy? As this study also examined an intensive day program, the question of dosage arises. We can speculate that the intensive frequency and duration of sessions likely allowed for a richer activation of past family dynamics. As many settings provide less frequency and duration of sessions, such as weekly outpatient sessions, there is the question of whether a minimum dosage of therapy is required, and whether a dose-response curve might be observed with regard to the intensity of therapy as another potential influence on improvement in quality of life as mediated by family re-enactment. At a more fundamental level, 
future investigations also need to consider the necessary mechanisms for change in alexithymia itself. Whether alexithymia is modifiable is a topic of persistent controversy. However, a recent review has demonstrated that alexithymia is a malleable construct (Ogrodniczuk et al. 2018). Indeed, we have previously reported that improvements in alexithymia are predictive of better health in the future, demonstrating less severe interpersonal problems among psychiatric outpatients following treatment in the same integrated group therapy program as described in the present study (Ogrodniczuk et al. 2012). Future studies into these questions could be fruitful in clarifying and more widely generalizing our results.

\section{CONCLUSION}

In conclusion, family re-enactment emerged as a significant mediator between alexithymia and improved quality of life in this intensive group psychotherapy setting. Consequently, clinicians working with individuals with alexithymia may consider a focus on the recapitulation of the family experience and how members' early family life experiences may have restricted their capacity to understand, modulate and share emotions, as it comes alive in the social microcosm of the therapy group. In this way, the group provides a fertile space to gain interpersonal feedback and practice healthier ways of relating emotionally to one's self and others in a way that enhances life functioning.

\section{Acknowledgements: None.}

\section{Conflict of interest: None to declare.}

\section{Contribution of individual authors:}

Study conception and design: John Ogrodniczuk \& Ingrid Söchting;

Data collection: John Ogrodniczuk \& Ingrid Söchting;

Statistical analysis and interpretation of the data: John Ogrodniczuk, David Kealy, Joanna Cheek \& Ingrid Söchting;

Writing of the manuscript: John Ogrodniczuk, David Kealy, Joanna Cheek \& Ingrid Söchting;

Manuscript drafts review: John Ogrodniczuk, David Kealy, Joanna Cheek \& Ingrid Söchting.

\section{References}

1. Bagby RM, Taylor GJ, Parker JDA: The twenty-item Toronto Alexithymia Scale - II. Convergent, discriminant, and concurrent validity. J Psychosom Res 1994; 38:33-40

2. Berenbaum H, James T: Correlates and retrospectively reported antecedents of alexithymia. Psychosom Med 1994: 56:353-359
3. Cameron K, Ogrodniczuk JS, Hadjipavlou G: Changes in alexithymia following psychological intervention: $A$ review. Harv Rev Psychiatry 2014; 22:162-178

4. Frisch MB: QOLI or Quality of Life Inventory. Pearson Assessments (formerly NCS Assessments), Minneapolis, 1994

5. Gatta M, Balottin L, Mannarini S, Chesani G, Del Col L, Spoto A, et al.: Familial factors relating to alexithymic traits in adolescents with psychiatric disorders. Clin Psychologist 2017; 21:252-262

6. Hayes $A F$ : Introduction to mediation, moderation, and conditional process analysis: A regression-based approach ( $2^{\text {nd }}$ ed.). Guilford, New York, 2018

7. Hayes AF, Rockwood NJ: Regression-based statistical mediation and moderation analysis in clinical research: observations, recommendations, and implementation. Behav Res Therapy 2017; 98:39-57

8. Hungr C, Ogrodniczuk JS, Söchting I: Alexithymia and locus of control among psychiatric outpatients. Int J Ment Health and Addiction 2016; 14:1047-1051

9. Karukivi M, Saarijrvi S: Development of alexithymic personality features. World J Psychiatry 2014; 4:91-102

10. King JL, Mallinckrodt B: Family environment and alexithymia in clients and non-clients. Psychotherapy Research 2000; 10:78-86

11. Kreitler $S$ : The psychosomantic approach to alexithymia. Personal Individ Differences 2002; 33:393-407

12. Lumley MM, Mader C, Gramzow J, Papineau K: Family factors related to alexithymia characteristics. Psychosom Med 1995; 58:211-216

13. MacNair-Semands RR, Ogrodniczuk JS, Joyce AS: Structure and initial validation of a short form of the Therapeutic Factors Inventory. Int $J$ Group Psychotherapy 2010; 60:245-281

14. Meganck R, Vanheule S, Inslegers R, Desmet M: Alexithymia and interpersonal problems: a study of natural language use. Personal Individ Differences 2009; 47:990995

15. Nemiah JC, Sifneos PE: Psychosomatic illness: A problem in communication. Psychother Psychosom 1970; 18:154-160

16. Ogrodniczuk JS, Kealy D, Hadjipavlou GA, Cameron K: Therapeutic issues. In Luminet $O$, Bagby RM \& Taylor GJ (eds): Alexithymia: Advances in Research, Theory, and Clinical Practice, 190-206. Cambridge University Press, 2018

17. Ogrodniczuk JS, Piper WE, Joyce AS: Alexithymia as a predictor of residual symptoms in depressed patients who respond to short-term psychotherapy. Amer $J$ Psychotherapy 2004; 58:150-161

18. Ogrodniczuk JS, Sochting I, Piper WE, Joyce AS: A naturalistic study of alexithymia among psychiatric outpatients treated in an integrated group therapy program. Psychol Psychother 2012; 85:278-291

19. Quilty L, Taylor GJ, McBride C, Bagby RM: Relationships among alexithymia, therapeutic alliance, and psychotherapy outcome in major depressive disorder. Psychia Res 2017; 254:75-79

20. Rutan JS, Stone WN, Shay JJ: Psychodynamic Group Psychotherapy: $5^{\text {th }}$ Edition. Guilford Press, New York, 2014

21. Sifneos PE: The prevalence of alexithymic characteristics in psychosomatic patients. Psychother Psychosom 1973; 22:255-262 
22. Sullivan HS: The collected works of Harry Stack Sullivan. Norton, New York, 1953

23. Taylor GJ: Symbolism, symbolization, and trauma in psychosomatic theory. In: Aisenstein M, Rappoport de Aisemberg E. (eds), Psychosomatics Today. A Psychoanalytic Perspective 181-199. Karnac, 2010

24. Taylor GJ, Bagby RM, Parker JDA: Disorders of affect regulation: Alexithymia in medical and psychiatric illness. Cambridge University Press, Cambridge, 1997

25. Taylor GJ, Bagby RM, Parker JDA: What's in the name 'alexithymia'? A commentary on "Affective agnosia: Expansion of the alexithymia construct and a new opportunity to integrate and extend Freud's legacy". Neuroscience and Biobehavioral Reviews 2016; 68:1006-1020

26. Thomas MD, McGrath A, Skilbeck CE: Psychometric properties of the QOLI. Austral J Psychology 2012; 64:225-234

27. Watters CA, Taylor GJ, Ayearst LE, Bagby RM: Measurement invariance of English and French language versions of the 20-item Toronto Alexithymia Scale. Europ J Psychological Assessment 2019; 35:29-36

28. Yalom ID, Leszcz M: The theory and practice of group psychotherapy (5th ed.). Basic Books, New York, 2005

Correspondence:

Professor John Ogrodniczuk, PhD

Department of Psychiatry, University of British Columbia

\#420-5950 University Boulevard, Vancouver, BC, V6T 1Z3, Canada

E-mail: john.ogrodniczuk@ubc.ca 